\title{
DEMOCRACIA Y ESTRATEGIAS DE DESARROLLO EN AMÉRICA LATINA Y ASIA ORIENTAL DURANTE LA SEGUNDA MITAD DEL SIGLO XX
}

Gabriel de la Paz*

\begin{abstract}
RESUMEN: El propósito del autor es presentar evidencia empírica que apoye la hipótesis general de que los cambios políticos en un país están estrechamente ligados a la evolución de su estructura socioeconómica. Con este objetivo, el autor describe las características fundamentales de las estrategias de desarrollo de cuatro países (Corea del Sur, Taiwán, México y Brasil) y explica su relación con el desarrollo político en cada uno de ellos. Con el fin de analizar esta relación, el autor presenta un panorama de la evolución de la distribución del ingreso durante la segunda mitad del siglo XX y lo contrasta con el progreso de las libertades políticas y civiles en los cuatro países. La evidencia presentada permite inferir que las estrategias de desarrollo "excluyentes" seguidas por los países latinoamericanos han sido adversas para la democratización.

Palabras Clave: Democracia, Desarrollo económico, Distribución del ingreso, Pobreza, Modelos de desarrollo, Estado, Sociedad civil.
\end{abstract}

\section{INTRODUCCIÓN}

Las estrategias de desarrollo económico que las élites políticas eligen ¿afectan significativamente el proceso de democratización de un país? Creo que hay buenas razones, evidencia empírica, que permiten responder que sí. Por lo tanto, deben haber factores estructurales que expli-

* Instituto Federal Electoral (delapaz@ correo.ife.org.mx). 
quen en gran medida el éxito o fracaso de la transición y consolidación democráticas en diferentes países y regiones. En otras palabras, la voluntad y habilidad del liderazgo político y la ingeniería institucional son insuficientes para garantizar la estabilidad y el buen funcionamiento de la democracia; hay ciertas condiciones socioeconómicas que a largo plazo facilitan o inhiben el desarrollo de las instituciones democráticas. Y estas condiciones son producto de las estrategias de desarrollo ("paquetes" de políticas públicas) que las autoridades estatales eligen, unas veces con relativa autonomía, otras dentro de estrechos límites impuestos por las fuerzas sociales internas y la estructura de poder internacional.

Mi propósito al escribir este ensayo es explicar por qué ciertas estrategias de desarrollo, que por su impacto social pueden llamarse "excluyentes", son menos favorables para la democratización que otras, y así demostrar que los cambios políticos de un país no son independientes de la evolución de su estructura socioeconómica. No es mi intención defender el determinismo económico, pero tampoco creo que el estudio de la política pueda aislarse de factores sociales y económicos que forman las estructuras de poder informal. Como propone Amartya Sen, es necesario "realizar un análisis integrado de las actividades económicas, sociales y políticas”, para establecer nexos empíricos entre las libertades políticas y las variables de desarrollo socioeconómico. ${ }^{1}$

El análisis que presento a continuación se centra en el pasado inmediato de América Latina: en las características de las estrategias de desarrollo predominantes durante la segunda mitad del siglo XX, las cuales, como intentaré demostrar, han limitado el desarrollo de la democracia en el presente y lo seguirán haciendo en el futuro. Para ilustrar mis argumentos he seleccionado los casos de Brasil y México. Dos países de Asia Oriental, Corea del Sur y Taiwán, sirven como contraste para resaltar la clave que explica la experiencia de los países latinoamericanos.

${ }^{1}$ Amartya Sen, Desarrollo y libertad, México, Planeta, 2000, pp. 16-17. 
Comienzo el ensayo con una breve introducción teórica sobre la relación positiva entre crecimiento económico y democracia. Aquí destaco el crucial papel que en esta relación desempeñan la distribución del ingreso y la igualdad social en general. Posteriormente describo las adversas condiciones socioeconómicas que históricamente han caracterizado a los países de Latinoamérica, para, en la sección siguiente, explicar cómo las estrategias de desarrollo excluyentes han generado esta situación de pobreza y desigualdad extremas. Finalmente establezco el nexo causal entre, por un lado, las estrategias de desarrollo excluyentes y sus efectos en la estructura social y, por el otro, los resultados de los procesos de democratización al finalizar el siglo XX, con lo cual demuestro que los problemas de las democracias latinoamericanas se deben en gran medida al impacto que los modelos de desarrollo económico han tenido en la estructura socioeconómica de la región durante las últimas décadas.

\section{DISTRIBUCIÓN DE LA RIQUEZA: PUENTE ENTRE CRECIMIENTO Y DEMOCRACIA}

Hace más de cuatro décadas Seymour Martin Lipset destacó la relación positiva entre desarrollo económico y democracia. Desde entonces un nutrido grupo de politólogos ha continuado trabajando en esta línea de investigación. En general, la literatura sobre el tema ha reforzado la tesis principal del ya clásico Political Man. ${ }^{2}$ Difícilmente podría ser de otra manera, pues la evidencia empírica no deja lugar a ambigüedades ${ }^{3}$

${ }^{2}$ Seymour Martin Lipset, Political Man. The Social Bases of Politics, Nueva York, Doubleday, 1960.

${ }^{3}$ Al respecto, Adam Przeworski presenta algunos datos interesantes: entre 1950 y 1990 "ningún régimen democrático ha caído jamás en países cuya renta per capita fuera superior a la de Argentina en 1976 (más de 6000 dólares)" mientras que "en los países con renta inferior a 1000 dólares... la esperanza de vida de los regímenes democráticos...es ligeramente superior a ocho años" (véase "Hermanas virtuosas: riqueza y democracia", Nexos, núm. 298, octubre, 2002, p. 58). 
— tanto así que incluso resulta ocioso señalar el hecho visible de que las democracias más estables del mundo son al mismo tiempo las más prósperas (con algunas raras excepciones que confirman la regla, como es el polémico caso de la India).

La relación positiva entre riqueza y democracia, sin embargo, dista de ser simple y lineal. El crecimiento económico no siempre es promotor de democratización, como lo demuestra la experiencia del Cono Sur durante los decenios de 1960 y 1970, años caracterizados por la combinación de crecimiento económico y establecimiento de dictaduras militares. Para aclarar esta aparente contradicción es necesario tomar en cuenta una importante variable que media entre crecimiento y democracia: la distribución del ingreso.

La distribución del ingreso puede acelerar o inhibir los efectos positivos del crecimiento económico en la democratización — definida esta última como establecimiento y consolidación de regímenes democráticos- es decir, regímenes que se basan en los principios de igualdad política y control popular sobre el gobierno por medio de elecciones libres, imparciales y frecuentes, en un marco de respeto a las libertades civiles (como las de expresión y asociación, entre otras). Así, volviendo a nuestro ejemplo, lo que sucedió en el Cono Sur se puede explicar porque la concentración del ingreso anuló la influencia positiva que pudo haber tenido el crecimiento económico para mantener y consolidar la democracia en aquella región. ${ }^{4}$

Parece ser, entonces, que el impacto del crecimiento económico en la democratización depende en gran parte de las pautas de distribución de la riqueza generada. Para ser más precisos: el crecimiento económico favorece la democratización cuando está ligado a un sistema de distribución equitativa del ingreso. El desarrollo económico, entendido como

${ }^{4}$ Véase Edward N. Muller, "Economic Determinants of Democracy", en Manus I. Midlarsky [ed.], Inequality, Democracy and Economic Development, Cambridge, Cambridge University Press, 1997, p. 134. 
crecimiento acompañado de distribución equitativa, es condición favorable para la democracia porque tiene consecuencias sociales igualadoras o equilibrantes: transforma la estructura social y modifica el balance de poder dentro de ella, pues amplía y fortalece los sectores medios y trabajadores de la población, incrementa los niveles de educación y genera una sociedad civil más densa y vigorosa, la cual constituye un espacio para la acción colectiva organizada de los grupos sociales anteriormente excluidos de la toma de decisiones políticas. ${ }^{5}$

En resumen, el desarrollo económico ofrece a las clases subordinadas nuevos instrumentos y oportunidades de acción organizada, y de esta forma reduce desigualdades sociales extremas, lo cual es crucial para la democracia - idea nada novedosa, por cierto, ésta de que la igualdad social es condición indispensable para el buen funcionamiento de la democracia, pues Aristóteles ya lo expresaba así en La Política, aunque refiriéndose, claro está, a democracias de otro tipo; ya en la era moderna otro pensador clásico, Alexis de Tocqueville, argumentaba lo mismo. En última instancia, la democracia puede definirse esencialmente como "el grado en el que el poder político de la élite es minimizado y el de la no élite es maximizado". ${ }^{6}$

Hay una inevitable tensión entre democracia y desigualdad social. Si bien cualquier definición de democracia implica la participación directa o indirecta de la mayoría en las decisiones de gobierno, es obvio que en las sociedades capitalistas modernas los individuos que forman la mayoría poseen menos recursos, educación y poder para participar. En los países económicamente desarrollados esta tensión entre desigualdad y democracia es relativamente moderada y no representa un grave problema para las instituciones democráticas. Pero no en todas partes sucede así, pues la democracia "resulta difícil en una situación de desigual-

${ }^{5}$ Véase Dietrich Rueschemeyer, Evelyne H. Stephens y John D. Stephens, Capitalist Development an Democracy, Cambridge, Polity Press, 1992, p. 50.

${ }^{6}$ Kenneth A. Bollen, "Issues in the Comparative Measurement of Political Democracy", American Sociological Review, núm. 45, 1980, p. 372. 
dades concentradas en la que una gran mayoría empobrecida se enfrenta con una oligarquía pequeña y rica". ${ }^{7}$ Ésta es precisamente la situación que históricamente ha imperado en América Latina.

\section{POBREZA Y DESIGUALDAD: EL ESTIGMA LATINOAMERICANO}

La introducción de instituciones liberales y democráticas en América Latina se remonta a finales del siglo XIX y principios del XX; cronológicamente no hay una diferencia significativa con respecto al surgimiento de los regímenes democráticos en Europa Occidental. No obstante, ha sido el autoritarismo en sus diversas modalidades, y no la democracia, lo que ha predominado en la realidad política latinoamericana. La historia de la democracia en esta región del planeta es de inestabilidad, interrupciones y quiebras; es la historia de una aspiración que sólo en casos excepcionales se ha visto materializada en las prácticas cotidianas de la competencia por el poder. ${ }^{8}$

Aunque ya han transcurrido casi dos décadas desde que la mayor parte de los países latinoamericanos se subieron a la tercera ola de democratización, este proceso, aunque relativamente exitoso, sigue mostrando, en no pocos casos, síntomas de fragilidad. Ya iniciado el nuevo milenio, la democracia en nuestras sociedades latinoamericanas sigue pareciendo incompleta e inestable.

La causa de que la democracia no haya podido echar raíces en Latinoamérica ha sido buscada en diferentes conjuntos de variables relacionadas, ya sea con factores estructurales como la cultura política y las condiciones socioeconómicas, ya sea con factores coyunturales

7 Samuel P. Huntington, La terecera ola, Barcelona, Paidós, 1994, p. 71.

${ }^{8}$ Laurence Whitehead presenta un interesante panorama del accidentado camino que ha tenido que recorrer la democracia en América Latina en "Democracy in Latin America since 1930", en Leslie Bethell [ed.], Latin America Politics and Society since 1930, Cambridge, Cambridge University, 1998, pp. 3-66. 
como la falta de voluntad de las élites políticas y las deficiencias de los diseños institucionales (especialmente los problemas de los sistemas presidenciales). Si bien la explicación del fenómeno debe ser multicausal, como lo es siempre en las ciencias sociales, probablemente los factores de mayor peso sean los socioeconómicos, como lo demuestran Gasiorowski y Power en una investigación llevada a cabo a finales del siglo pasado, cuyos resultados revelan que no son el régimen presidencial, la fragmentación de los partidos políticos ni los valores tradicionales, sino los factores relacionados con el grado de desarrollo económico los que afectan significativamente la consolidación democrática en el Tercer Mundo. ${ }^{9}$ Como se sugirió en la sección precedente, la influencia del crecimiento económico en la democratización depende de los efectos igualadores de dicho crecimiento en la estructura social. Si lo anterior es cierto, podemos inferir que el principal obstáculo para la democracia en América Latina ha sido la desigualdad social, la cual está lógicamente ligada con los altos índices de pobreza característicos de la zona.

En efecto, entre las regiones más pobres del mundo, América Latina es además la que presenta los más altos índices de concentración del ingreso. Y esta situación responde a una tendencia histórica. En tres cálculos sucesivos que hizo el Banco Mundial de la proporción del ingreso que reciben los habitantes que integran la quinta parte más pobre de la población en las diferentes regiones del mundo, resultó que sólo en América Latina esta proporción había disminuido persistentemente. ${ }^{10} \mathrm{~A}$ principios del decenio de 1990, los hogares incluidos dentro de la quinta parte más pobre del área recibían menos de $4 \%$ del ingreso total, mientras que esa misma proporción de hogares, pero en el grupo de los más ricos, se quedaban con 40\%: una diferencia de diez a uno, la cual en el

9 Véase Mark J. Gasiorowski y Timothy J. Power, "The Estructural Determinants of Democratic Consolidation. Evidence from the Third World", Comparative Political Studies, vol. 31, núm. 6, 1998, p. 23.

10 J. Sheahan, Patterns of development in Latin America, Nueva Jersey, Princeton University, 1987, p. 23. 
resto de los países en desarrollo era de siete a uno, y en los países desarrollados de cinco a uno. ${ }^{11}$ Esta situación de desigualdad se ha agravado, o por lo menos mantenido, en la mayoría de los países latinoamericanos durante los últimos años; lo mismo el elevado número de pobres, que durante las últimas décadas ha oscilado, según cálculos conservadores, alrededor de $45 \%$, es decir que prácticamente la mitad de la población de esta zona del mundo vive en condiciones de pobreza. ${ }^{12}$ Otra clara evidencia de desigualdad social en la región es el bajo nivel educativo de sus habitantes, ya que, aunque el analfabetismo ha disminuido en las últimas décadas, todavía hay una diferencia notable con respecto a los países desarrollados. En 1995, por ejemplo, la tasa de analfabetismo en América Latina era de 10.2\%, mientras que en Estados Unidos era de $0.5 \% .^{13}$

Pobreza y desigualdad en América Latina han generado una rígida estructura social, en la cual el poder económico y político es concentrado por la minoría, mientras que un amplio sector de la sociedad se encuentra marginado del desarrollo social. Esta asimétrica estructura de poder dificulta la toma de decisiones democráticas y su ejecución, no sólo porque la poderosa minoría tiene los recursos suficientes para resistirse ante cualquier política democrática contraria a sus intereses, sino también porque un significativo porcentaje de la población carece de la

${ }^{11}$ Datos tomados de Thomas Skidmore y P. H. Smith, Modern Latin America, Oxford, Oxford University, 1992, p. 61; y de Victor Bulmer-Thomas, The New Economic Model in Latin America and Its Impact on Income Distribution and Poverty, Londres, MacMillan/University of London, 1996, p. 7.

12 Según cálculos de la CEPAL, el porcentaje de personas ubicadas bajo la línea de pobreza disminuyó de 48.5 a 43.5 durante el periodo 1990-1997; sin embargo, a causa de las crisis económicas, la pobreza aumentó a 44\% en el 2002. Véase "Siete millones más de pobres en Latinoamérica en 2002: CEPAL”, La Jornada, México, 8 de noviembre, 2002, p. 25.

13 Véase Rosemary Thorp, Progress, Poverty and Exclusion: An Economic History of Latin America in the $20^{\text {th }}$ Century, Washington, D.C., Banco Interamericano de Desarrollo, 1998, p. 36. 
seguridad material y la educación necesarias para ejercer de manera efectiva sus derechos ciudadanos e influir en el gobierno.

La pobreza no es por sí misma un obstáculo insalvable para la democracia, y la India es el ejemplo, aunque no exento de polémica, que se suele citar para probar esta afirmación. De cualquier forma, la India presenta niveles de desigualdad menores que los de Latinoamérica. Lo anterior nos lleva a pensar que es la particular combinación de pobreza y desigualdad extremas lo que determina la naturaleza incompleta e inestable de las democracias latinoamericanas. Por un lado, las masas empobrecidas ejercen con sus demandas una intensa presión política, frecuentemente por fuera de las instituciones legales, sobre los gobiernos democráticos; por el otro, "cualquier intento de reducir la riqueza, el poder y la impunidad de las élites [...] ha provocado inevitablemente su ira y reacción". ${ }^{14}$ Y si las élites concentran un poder excesivo, serán sus intereses los que finalmente marquen el rumbo de las políticas gubernamentales. Sin embargo, la democracia es, en términos normativos, un sistema incluyente, basado en la igualdad política y la participación de la mayoría en el gobierno. Es claro, entonces, que el modelo económico y político que ha predominado en América Latina produce efectos adversos para la democracia.

\section{LAS ESTRATEGIAS DE DESARROLLO EXCLUYENTES DE AMÉRICA LATINA}

Las condiciones socioeconómicas descritas en la sección anterior son resultado del tipo de estrategias de desarrollo que se han seguido en América Latina. Y aquí hay que destacar que pobreza y desigualdad no son consecuencia de falta de crecimiento únicamente, ni de algún mode-

${ }^{14}$ Jorge G. Castañeda, "Democracy and Inequality in Latin America: A Tension of the Times”, en Domínguez y Lowenthal [eds.], Constructing Democratic Governance. Latin America and the Caribbean in the 1990s, Baltimore, Johns Hopkins University, 1996, pp. 59-61. 
lo económico en particular. Veamos algunos ejemplos. Entre 1970 y 1980 la política económica proteccionista e intervencionista del Estado mexicano logró una tasa de crecimiento media anual de más de 6\%. Si bien mejoró en general la calidad de vida de la población, la expansión económica no redujo la desigualdad. ${ }^{15}$ Siguiendo el camino opuesto, el de las radicales políticas de libre mercado, Pinochet hizo que Chile registrara altas tasas de crecimiento durante la década de 1980; sin embargo, hacia 1990 la sociedad chilena era más desigual que antes de que Pinochet iniciara su reforma económica. ${ }^{16}$ En ambos casos, el crecimiento, alcanzado por medio de diferentes modelos económicos, no fue suficiente para evitar el aumento de la desigualdad y reducir significativamente la pobreza. En contraste, durante las últimas décadas del siglo XX, algunos países de Asia Oriental adoptaron estrategias de desarrollo que les permitieron crecer aceleradamente y distribuir el ingreso de forma relativamente equitativa. Llama la atención que la transición democrática en estos países asiáticos haya sido más exitosa que en la mayoría de los latinoamericanos. Parece lógico suponer que, a diferencia de América Latina, los efectos igualadores de las estrategias de desarrollo aplicadas en países como Corea del Sur y Taiwán favorecieron sus procesos de democratización.

Desde la perspectiva neoclásica, el éxito de los países del este asiático se atribuye a la superioridad del sistema de libre mercado. Consecuentemente, el fracaso de las estrategias de desarrollo en América Latina se explica por las distorsiones generadas por la intervención estatal. Esta explicación, sin embargo, ignora que también en aquellos países fue significativa la intervención estatal en la economía, lo cual indica que en realidad "el mejor desempeño económico en Asia Oriental no se debe simplemente [...] al grado de intervención estatal, sino a la efectividad de la intervención". Y esta efectividad depende de que la estructura del

15 Véase Soledad Loaeza, “Desigualdad y democracia”, Nexos, núm. 123, 1988.

16 Véase Castañeda, op. cit., p. 57. 
aparato estatal favorezca la autonomía de las autoridades que representan al Estado. La autonomía estatal fue relativamente más amplia en Asia Oriental que en América Latina. Consecuentemente, en la primera región el Estado "desempeñó un papel más importante al dirigir las inversiones hacia actividades productivas con una visión de desarrollo a largo plazo, lo cual contribuyó al rápido crecimiento industrial en Asia Oriental. Al contrario, el desarrollo truncado en América Latina fue resultado de una intervención estatal menos efectiva". ${ }^{17}$

Antes de continuar es necesario dejar claro que una estrategia de desarrollo es una combinación de políticas públicas que incluyen tanto políticas industriales como de bienestar social, pues factores como educación y salud son fundamentales para el desarrollo de cualquier sociedad. De acuerdo con esta definición, es correcto afirmar que en América Latina se han seguido estrategias de desarrollo "excluyentes". Con base en los datos y argumentos que Haggard presentó en uno de los trabajos más interesantes sobre el tema, ${ }^{18}$ trataré de esclarecer el significado del término "estrategia de desarrollo excluyente" mediante un análisis comparativo. Con este propósito, a continuación describiré brevemente el desempeño del Estado en aspectos fundamentales de la estrategia de desarrollo (políticas agrícola, educativa e industrial, y los efectos de estas políticas en la estructura social) en cuatro países: México, Brasil, Corea del Sur y Taiwán, durante el periodo de 1960 a 1980.

Entre 1960 y 1980, en América Latina el modelo de desarrollo predominante era el conocido como de sustitución de importaciones. La

${ }^{17}$ John Borrego et al., Capital, the State, and Late Industrialization: Comparative Perspectives on the Pacific Rim, Boulder, Westview, 1996, p. 15. De manera similar, Stephen Haggard afirma que las características del Estado como institución, particularmente el grado de autonomía frente a las fuerzas sociales, son cruciales para entender los procesos de toma de decisiones y ejecución de políticas públicas (véase Pathways from the Periphery. The Politics of Growth in the Newly Industrializing Countries, Nueva York, Cornell University, 1990, p. 46).

${ }_{18}$ Me refiero al libro, lamentablemente no tan conocido en México, Pathways from the Periphery... 
intervención estatal dentro de este modelo, aunque permitió que países como México y Brasil lograran un crecimiento acelerado, provocó también mayor desigualdad mediante el aumento en la concentración del ingreso. Durante el mismo periodo, Corea del Sur y Taiwán, siguiendo el modelo de economía exportadora, combinaron crecimiento con una distribución del ingreso relativamente equitativa (véase el cuadro 1).

\section{Cuadro 1. Proporción del ingreso que reciben los hogares que integran el $40 \%$ más pobre de la población.}

\begin{tabular}{ll}
\hline & $40 \%$ inferior \\
\hline Corea del Sur & 18.0 \\
1964 & 18.0 \\
1970 & 16.9 \\
1976 & \\
Taiwán & 11.3 \\
1964 & 20.3 \\
1972 & 21.8 \\
1980 & \\
Brasil & \\
1960 & $8.0-11.5$ \\
1970 & $6.8-9.9$ \\
1976 & $6.8-9.9$ \\
México & \\
1957 & $11.3-15.5$ \\
1963 & $9.2-10.3$ \\
1977 & $8.0-8.2$ \\
\hline
\end{tabular}

FUENTE: Stephen Haggard, Pathways from Periphery, Nueva York, Cornell University, 1990, p. 229. 
Los principales factores que explican la diferencia en la distribución del ingreso entre los cuatro países mencionados son: a) la propiedad de la tierra, b) el acceso a la educación y c) la estrategia de industrialización. Respecto al primer factor, es cierto que, como resultado de reformas agrarias previas en Corea y Taiwán, en el decenio de 1960 estos países presentaban niveles de desigualdad rural menores que los de México y Brasil. Sin embargo, la persistencia de la desigualdad y pobreza rurales en los dos países latinoamericanos está relacionada con las políticas gubernamentales puestas en práctica en ese sector: políticas de precios y apoyos que favorecieron a los grandes propietarios y promovieron técnicas de uso intensivo del capital, además de presentar marcadas diferencias regionales en la distribución de infraestructura, irrigación y nuevas tecnologías, y disminuir la inversión y el financiamiento públicos para el sector rural, en comparación con otros sectores. ${ }^{19}$

En cuanto a la educación, la diferencia entre los países latinoamericanos y los asiáticos es contrastante, como lo demuestra, por ejemplo, el hecho de que al iniciar el decenio de 1980 la matrícula en el nivel de educación secundaria en Corea del Sur duplicaba, en términos relativos, a las de México y Brasil. ${ }^{20} \mathrm{Si}$ el acceso a la educación es uno de los factores determinantes para reducir la desigualdad social, se puede decir que, a diferencia de lo que sucedió en América Latina, las políticas de inversión pública en educación llevadas a cabo eficazmente en los países de Asia Oriental fueron una de las claves para la formación de sociedades más igualitarias.

Finalmente, es importante destacar algunos efectos de la política industrial en la distribución del ingreso. En general, incentivos para el uso intensivo de la mano de obra en la industria, como los que fueron adoptados en los países de Asia Oriental, promueven una distribución del ingreso más equitativa en economías donde la mano de obra es abun-

${ }^{19}$ Ibid., p. 236.

${ }^{20}$ Ibid., p. 239. 
dante, en comparación con las estrategias basadas en el de uso intensivo de capital. ${ }^{21}$ No obstante, las políticas derivadas del modelo de sustitución de importaciones en México y Brasil promovieron estrategias de industrialización intensivas en capital. Esto fue causa fundamental de problemas tales como el lento crecimiento del empleo, la expansión del sector informal y, motivadas por la gran diferencia entre los salarios en la agricultura y en la industria, las migraciones rurales masivas hacia las zonas urbanas. Todo lo anterior contribuyó a incrementar la desigualdad social.

Los efectos que el modelo de sustitución de importaciones tuvo en la estructura social en México y en Brasil permiten afirmar que las estrategias de desarrollo que estos países llevaron a cabo fueron excluyentes, pues amplios sectores de la población quedaron prácticamente marginados de los beneficios del crecimiento económico; así lo indican la persistente pobreza y creciente desigualdad en la región hacia finales del decenio de 1970. Sin embargo, en la década siguiente la mayor parte de los países latinoamericanos, obligados por la crisis de la deuda externa, dieron un golpe de timón y comenzaron un proceso de ajuste y reestructuración económicos, cuyo propósito era y sigue siendo el de integrarse al mercado mundial e impulsar el crecimiento mediante las exportaciones. Este modelo de "modernización via internacionalización —orientación de la producción y el consumo conforme a los precios y prácticas de los mercados internacionales_-", 22 conocido también como "consenso de Washington", fue la pauta para que los diferentes gobiernos latinoamericanos, actuando dentro de los límites que las condiciones políticas de cada país imponía, establecieran las líneas fundamentales de sus nuevas estrategias de desarrollo. El paquete de políticas básicas de este nuevo modelo, cuya piedra angular era la liberalización comercial, incluía, entre otras, la reducción del déficit público mediante la disciplina fiscal, la

${ }^{21}$ Ibid., p. 224.

22 Adam Przeworki et al., Democracia sustentable, Buenos Aires, Paidós, 1998, p. 26. 
eliminación de subsidios, la liberalización de las tasas de interés y de cambio, y la privatización de empresas estatales. Pueden decirse muchas cosas a favor y en contra del modelo neoliberal, lo cierto es que a varios lustros de su implantación la pobreza y la desigualdad siguen aumentando en América Latina. ${ }^{23}$

Como ya se mencionó anteriormente, según cálculos de la CEPAL, al despuntar el siglo XXI prácticamente la mitad de la población latinoamericana vivía en condiciones de pobreza. Esto no es sólo consecuencia de la falta de crecimiento económico. De hecho no hay una relación automática entre altas tasas de crecimiento y disminución de pobreza. Dicha relación depende de que el crecimiento vaya acompañado de la creación de empleos de calidad, lo cual no ha sido el caso en la mayoría de los países de América Latina: “esto explica por qué en muchos países el crecimiento económico no se ha traducido en una reducción proporcional de la pobreza". ${ }^{24}$

Los cambios en la distribución del ingreso en Latinoamérica varían dependiendo de cada país, sin embargo "quizá no haya un solo país en la región en el cual la desigualdad sea menor a la de hace tres décadas [...], y en muchos países la desigualdad es mucho mayor hoy en día". ${ }^{25}$

${ }^{23}$ Es importante hacer notar que aunque ambos modelos de desarrollo, el de sustitución de importaciones y el que podemos llamar neoliberal, generaron alta concentración del ingreso; en términos absolutos la evolución del ingreso muestra un cambio de tendencia muy importante durante la segunda mitad del siglo xx, pues mientras que en el modelo de sustitución de importaciones hubo notables incrementos en los ingresos, principalmente de los sectores medios y los trabajadores organizados, el modelo neoliberal detuvo e incluso revirtió esta tendencia positiva. Aunque la evolución del ingreso en términos absolutos es un indicador necesario para analizar el comportamiento general del ingreso, en este ensayo me limito a estudiar la relación entre distribución de ingreso y democracia, pues, de acuerdo con el marco teórico de este trabajo, la distribución del ingreso es la variable significativa para explicar el desarrollo democrático.

${ }^{24}$ CEPAL, Equity, Development and Citizenship (documento de trabajo presentado en la vigésimo quinta sesión de la CEPAL), México, 2000, p. 64.

${ }^{25}$ Loc. cit. 
De acuerdo con la CEPAL, las desigualdades son consecuencia de la combinación de factores relacionados con educación, demografía, ocupación y salud. Es claro que la pobreza y la desigualdad en Latinoamérica son problemas estructurales históricos que ya estaban allí antes de la adopción del modelo neoliberal. No obstante, este modelo económico no ha podido resolver los problemas, y en muchos casos los ha profundizado. Dos ejemplos pueden ilustrar lo anterior: primero, la devaluación real y la reducción del gasto público que acompañaron a los programas de ajuste estructural implicaron la caída de los salarios reales y el aumento del desempleo en el corto plazo; segundo, el generalmente lento crecimiento del volumen de exportaciones y el fracaso de la recuperación de la inversión privada han contribuido a continuar el desempleo (exacerbado por la pérdida de empleos en las empresas anteriormente protegidas). ${ }^{26} \mathrm{El}$ desempleo, claro está, es una variable económica fundamental para explicar el aumento de los niveles de desigualdad y pobreza.

Sea cual fuere la interpretación, el hecho es que en los países latinoamericanos, a diferencia de los de Asia Oriental, el modelo exportador no ha promovido el crecimiento ni tampoco ha logrado disminuir la concentración del ingreso. En otras palabras, cambió la estrategia de desarrollo en los años ochenta, pero siguió siendo una estrategia excluyente.

\section{DESARROLLO Y DEMOCRACIA}

Corea del Sur, Taiwán, Brasil y México son parte de lo que Huntington llamó la tercera ola de la democracia. Los dos primeros países comenzaron su transición democrática a mediados de los años ochenta. Poco antes había sido elegido en Brasil el primer presidente civil desde

${ }^{26}$ Estos y otros efectos de las políticas neoliberales en la distribución del ingreso y la pobreza pueden consultarse en E.V.K. FitzGerald, "The new Trade Regime, Macroeconomic Behaviour and Income Distribution in Latin America”, en BulmerThomas, op. cit., p. 50. 
1964, mientras que México continuaba su lenta y gradual apertura política iniciada en los años setenta. Si al iniciar el decenio de 1980 los cuatro países tenían sistemas políticos autoritarios, al finalizar el siglo XX las diferencias políticas entre los países asiáticos y los latinoamericanos eran evidentes (véase cuadro 2). Según la última encuesta anual del siglo XX aplicada por Freedom House, Corea del Sur y Taiwán ya eran entonces países libres de acuerdo con la evaluación de sus derechos políticos y libertades civiles, en cambio Brasil y México todavía eran parcialmente libres a causa de problemas relacionados con el respeto a los derechos humanos y, en general, con el cumplimiento de la ley.

CUADRo 2. Comparación del grado de libertad en cuatro países 1999-2000

País Derechos políticos Libertades civiles Evaluación

$\begin{array}{llll}\text { Corea del Sur } & 2 & 2 & \text { Libre } \\ \text { Taiwán } & 2 & 2 & \text { Libre } \\ \text { México } & 3 & 4 & \text { Parcialmente libre } \\ \text { Brasil } & 3 & 4 & \text { Parcialmente libre }\end{array}$

Valores: máximo 1 (libre); mínimo 7 (no libre).

FUENTE: Table of countries 1999-2000. Comparative measures of freedom. Freedom House. http://www.freedomhouse.org

De la experiencia de estos cuatro países puede inferirse que hay una significativa correlación entre igualdad social y democratización. Las estrategias de desarrollo en Corea del Sur y Taiwán promovieron el crecimiento en el contexto de esquemas relativamente igualitarios de distribución de la riqueza. En contraste, el acelerado crecimiento en Brasil y México durante el periodo de sustitución de importaciones estuvo relacionado con el aumento de la desigualdad, y como se ha visto, la posterior reforma neoliberal hasta ahora ha sido incapaz de abatir los índices 
de pobreza y desigualdad, si no los ha empeorado. No es coincidencia que hacia el final del milenio Corea del Sur y Taiwán habían avanzado más que Brasil y México en la creación y consolidación de sus respectivos sistemas políticos democráticos.

Los efectos igualadores de las estrategias de desarrollo de los países asiáticos generaron una amplia y educada clase media, la cual fue factor clave para impulsar la democratización de estos países. En Taiwán, los "principales agentes del cambio político" fueron "los recientemente aparecidos intelectuales de clase media, que crecieron durante el periodo de acelerado crecimiento económico". ${ }^{27}$ Y en Corea del Sur "el movimiento en pro de la democracia, en 1980, solamente se convirtió en una seria amenaza al régimen autoritario después de la aparición de una floreciente clase media urbana, y los profesionales de clase media se unieron a los estudiantes en la exigencia de que finalizara el autoritarismo". ${ }^{28}$ Haggard presenta una interpretación similar:

Al centrar la atención de las políticas públicas en el rol del trabajo para mantener la competitividad, el crecimiento basado en la promoción de exportaciones inclinó a las élites políticas y económicas hacia el control y/o exclusión política de la clase trabajadora. Esta inclinación redujo la base de posibles coaliciones de apoyo a la democracia, y de esta manera contribuyó a mantener sistemas políticos autoritarios o cerrados. No fue sino hasta que la clase media se expandió, producto del rápido desarrollo económico, cuando emergieron las nuevas presiones sociales por la democracia. ${ }^{29}$

En América Latina ha ocurrido lo contrario. Los altos niveles de pobreza y desigualdad impiden la expansión de la clase media e implican la existencia de amplios sectores de la sociedad que no pueden ejercer

27 Tun-jen Cheng, Democratizing the KMT Regimen in Taiwan, Taipei, Taiwán, 1989, p. 20, citado en Huntington, op. cit., p. 72.

${ }^{28}$ Ibid., p. 72.

${ }^{29}$ Haggard, op. cit., p. 255. 
plenamente sus derechos y obligaciones ciudadanos, lo cual está relacionado con la polarización política y la inestabilidad social en la región. Ciertamente no es éste un contexto favorable para el funcionamiento de instituciones democráticas. Por lo tanto no debe sorprendernos que las democracias latinoamericanas usualmente sean acompañadas de adjetivos que denotan una condición de insuficiencia: "democracias electorales", "democracias formales", "democracias delegativas", "democracias restrictivas", etc. Tampoco debería sorprendernos que América Latina siga siendo suelo fértil para el surgimiento de movimientos populistas. Las bases sociales que han apoyado a los líderes neo-populistas se encuentran principalmente entre la población pobre y desorganizada del sector informal de la economía. Cuando los líderes populistas de viejo o nuevo cuño logran ganar las elecciones, tienden a concentrar el poder y gobernar verticalmente, sin procedimientos claros de rendición de cuentas, lo cual representa serios retrocesos para la consolidación democrática, como lo demuestran las experiencias de Alberto Fujimori en Perú, y, más recientemente, Hugo Chávez en Venezuela. Mientras continúe la debilidad y descrédito de las instituciones políticas formales (autoridades del gobierno, representantes populares, jueces y partidos políticos), e importantes sectores sociales sigan siendo marginados del desarrollo social y económico, el populismo será, como hasta ahora, un fenómeno recurrente en la política latinoamericana.

En América Latina ninguna estrategia de desarrollo, ni el modelo de sustitución de importaciones ni la posterior reforma neoliberal ha logrado producir una amplia clase media y una vigorosa clase trabajadora, fuerzas sociales que permiten (aunque no necesariamente aseguran) el desarrollo de la democracia. Según explica Rueschemeyer: "si uno analiza las fuerzas que están detrás del éxito o fracaso de los intentos de instalar regímenes democráticos, las clases medias emergen como las fuerzas cruciales detrás de las alianzas que llevan a cabo los primeros avances hacia democracias restrictivas y, en colaboración con las clases trabajadoras, hacia democracias completas. Fueron las clases medias la base principal de los partidos y movimientos que ejercieron pre- 
sión a favor de la democracia". ${ }^{30}$ Ciertamente, la industrialización aumentó el potencial de las presiones pro democráticas "porque fortaleció la sociedad civil al incrementar el tamaño e interacción de las clases medias y trabajadoras"; sin embargo, en Brasil y México el uso intensivo de capital en la producción durante el periodo de sustitución de importaciones, y la incorporación del movimiento obrero al aparato corporativo estatal, impidieron el desarrollo de una clase obrera amplia y autónoma, y, por lo tanto, limitaron su capacidad para presionar a favor de la democratización. ${ }^{31}$ La debilidad y subordinación de la clase obrera fue también característica de las sociedades de Corea del Sur y Taiwán, pero en estos países, como hemos visto, una extensa e influyente clase media, producto del acelerado desarrollo económico con distribución igualitaria de la riqueza, fue la clave de la democratización. En contraste, las estrategias de desarrollo excluyente en los países de Latinoamérica, al preservar o aumentar la pobreza y la desigualdad en la región, han restringido la formación de clases medias amplias y vigorosas, como las de Corea del Sur y Taiwán, capaces de ejercer influencia efectiva para reforzar los procesos de transición y consolidación democráticas. Todo parece indicar que la ausencia de una sociedad civil desarrollada y fuerte, una amplia red de asociaciones autónomas que medien entre el Estado y la ciudadanía, ha sido uno de los obstáculos más importantes para la instalación y el funcionamiento de las instituciones democráticas en Brasil y México, como en muchos otros países de América Latina.

\section{OBSERVACIONES FINALES}

Las múltiples circunstancias y factores que han influido en la democratización de los cuatro países que fueron seleccionados para este ensayo

${ }^{30}$ Rueschemeyer, op. cit., p. 181.

${ }^{31}$ Ibid., p. 166. 
son vastas y complejas. No obstante, el somero análisis realizado en las páginas anteriores muestra que las disparidades en los niveles de igualdad social están muy probablemente relacionados con las diferencias en los ritmos y resultados de los procesos democratizadores de los países en cuestión. Los niveles de desigualdad social a su vez dependen en gran medida de los diferentes tipos de estrategias de desarrollo que guían las políticas públicas de cada país. De tal manera que, para los países en transición política, sea de gran importancia la elección del modelo de desarrollo económico, ya que de éste depende, en el largo plazo, la probabilidad de la democratización - y me refiero no sólo a la instalación de regímenes democráticos, sino también a la efectividad de las instituciones y la participación de la ciudadanía, es decir, a la profundidad y calidad de la democracia.

El surgimiento de las fuerzas sociales promotoras de la democracia es consecuencia del crecimiento económico, la distribución relativamente equitativa del ingreso, la inversión pública en educación y otras variables socioeconómicas que no dependen de que las élites políticas estén comprometidas con un proyecto democratizador. Es claro que los gobiernos de Corea del Sur y Taiwán no estaban pensando en iniciar la democratización de sus regímenes políticos cuando decidieron adoptar sus estrategias de desarrollo de economías exportadoras. Tampoco en Brasil ni en México los gobernantes estaban preocupados por encontrar el mejor camino hacia la democracia cuando basaron su proyecto de desarrollo en la sustitución de importaciones. El estado desarrollista no era necesariamente democrático. En el caso del modelo de desarrollo neoliberal, que en América Latina reemplazó al de sustitución de importaciones en los años ochenta, la situación es diferente. No sólo la transición democrática y la reforma económica han sido simultáneas, sino que frecuentemente se argumenta que ambas, democracia y liberalización económica, son complementarias - y eso cuando no se afirma con ligereza que se trata de lo mismo. De tal manera que todos lo gobiernos neoliberales han expresado, aunque se quede sólo en el discurso, sus aspiraciones democráticas y su compromiso con la modernización políti- 
ca. Sin embargo - y aquí ni siquiera vamos a discutir los estilos autocráticos de gobernar de presidentes neoliberales y "demócratas" como Carlos Salinas y Saúl Menem - las políticas neoliberales en general han contribuido a incrementar la pobreza y la desigualdad, las cuales, como hemos visto, son contrarias al desarrollo de la democracia. Por lo que no es erróneo afirmar que el camino seguido durante los últimos lustros por los reformistas latinoamericanos es incoherente. No se puede aspirar seriamente a la democracia, si al mismo tiempo se lleva a la práctica una estrategia económica que preserva, y en muchos casos aumenta, la extrema desigualdad social (la mayor del mundo) de los países latinoamericanos.

Para aumentar la probabilidad de construir y consolidar sistemas democráticos en América Latina sería necesario adoptar una estrategia de desarrollo diferente a la que domina en la región desde los años ochenta. Una estrategia que promueva la igualdad social, lo cual implica inevitablemente la intervención eficiente del Estado dirigida a imponer esquemas de distribución del ingreso más equitativos, a promover la creación de empleos y a invertir mucho más en educación. Éstos deben ser los ejes de la estrategia de desarrollo en América Latina, aunque no coincida a veces con la ortodoxia neoclásica, si realmente se quiere asegurar el éxito de la democracia en la región. Habrá quienes estén en desacuerdo, quienes aleguen que la intervención estatal ya demostró ser inútil, cuando no perversa. A ellos se les puede responder citando a Adam Przeworski: "cuando el Estado es reducido al punto de no poder proveer protección física y acceso a servicios sociales básicos, el orden público colapsa: la supervivencia material e incluso la seguridad física pueden quedar en manos privadas [...] Bajo esas condiciones, no sólo la democracia queda amenazada, sino también las bases mismas de la cohesión social". ${ }^{32}$

${ }^{32}$ Przeworski, op. cit., p. 163. 
BIBLIOGRAFÍA

Borrego, JoHn et al., Capital, the State, and Late Industrialization: Comparative Perspectives on the Pacific Rim, Boulder, Westview Press, 1996.

Bulmer-Thomas, Victor, The New Economic Model in Latin America and its Impact on Income distribution and Poverty, Londres, MacMillan/University of London, 1996.

CEPAL, Equity, Development and Citizenship (working document presented at the twenty-eight session of the commission), México, 3-7 de abril, 2000.

Chalmers, Douglas A. y Carlos M. Vilas, The New Politics of Inequality in Latin America: Rethinking Participation and Representation, Oxford, Oxford University Press, 1997.

Domínguez, JoRge I. and Abraham F. Lowenthal [eds.], Constructing democratic governance. Latin America and the Caribbean in the 1990s, Baltimore, Johns Hopkins University Press, 1996.

GASIOROWSKI, MARK J. y Timothy J. Power, "The Structural Determinants of Democratic Consolidation. Evidence from the Third World", Comparative Political Studies, vol. 31, núm. 6, 1998.

Haggard, Stephen, Pathways from the Periphery. The Politics of Growth in the Newly Industrializing Countries, Nueva York, Cornell University Press, 1990.

Huntington, Samuel P., The Third Wave. Democratization in the Late Twentieth Century, Oklahoma, University of Oklahoma Press, 1991.

Midlarsky, Manus I. [ed.], Inequality, Democracy and Economic Development, Cambridge, Cambridge University Press, 1997.

PRZEWORSKI, ADAM, Democracia sustentable, Buenos Aires, Paidós, 1998.

, "Hermanas virtuosas: riqueza y democracia", Nexos, núm. 298, 2002. 
RuESCHEMEYER, DiETRICH, Evelyne H. Stephens y John D. Stephens, Capitalist Development and Democracy, Cambridge, Polity Press, 1992.

Sen, Amartya, Desarrollo y libertad, México, Planeta, 2000.

Sheahan, J., Patterns of Development in Latin America, Nueva Jersey, Princeton University Press, 1997.

Skidmore, Thomas y P.H.Smith, Modern Latin America, Oxford, Oxford University Press, 1992.

Thorp, Rosemary, Progress, Poverty and Exclusion: An Economic History of Latin America in the $20^{\text {th }}$ Century, Washington, D.C., BID, 1998.

TOCQUEVILle, AleXIS DE, El antiguo régimen y la revolución, Madrid, Alianza, 1982. 